\title{
A Low Voltage Ion Transport System for External Ionization Fourier Transform Mass Spectrometry
}

\author{
Carl F. Ijames and Sanford P. Markey \\ Laboratory of Clinical Science, National Institute of Mental Health, Bethesia, Maryland, USA
}

\begin{abstract}
An efficient ion transport system that interfaces external ion sources with a commercial dual-cell Fourier transform mass spectrometry (FTMS) system so as to retain maximum experimental flexibility has been constructed. Electrostatic lenses were used for ion transfer with potentials less than $200 \mathrm{~V}$ to preclude discharges. Spectra were recorded by thermal ionization and by electrospray ionization. Other high pressure ionization methods can be easily added to the external ion source chamber, making this a general solution for ion transport into an FTMS system. The efficiency of ion transfer was measured to be approximately $30 \%$. A pressure ratio of $10^{5}$ between the external ion source chamber and the second cell has been demonstrated. The system incorporates a computer-controlled gate valve to isolate the cell regions from the external ion source chamber, permitting optimal conditions for ion injection and accumulation, and then after closing the valve, recording spectra at low pressure with high resolution. Spectra of Gramicidin S (resolution 90,000 at $\mathrm{m} / \mathrm{z} 1164$ ), aprotinin (resolution 410,000 at $\mathrm{m} / \mathrm{z}$ 1304), and horse heart cytochrome $c$ (resolution 50,000 at $m / z$ 1546) are shown. (/ Am Soc Mass Spectrom 1994, 5, 398-406)
\end{abstract}

$\mathrm{F}$ ourier transform mass spectrometry (FTMS) is well known as a high performance mass analysis technique, offering extremely high mass resolution and mass measurement accuracy, high mass-to charge ratio range, $\mathrm{MS}^{\mathrm{n}}$ capability, the ability to trap ions for extended periods to study their chemical and spectroscopic properties, and mechanically robust hardware. The two major limitations of FTMS are that the best performance is achieved at the lowest pressure (optimally well below $1 \times 10^{-8}$ torr), and the limited access to the trapped ion analyzer cell located in the center of a high-field superconducting magnet. Together, these make interfacing many ionication techuiques of current interest, such as liquid secondary ion mass spectrometry (LSIMS), high-pressure chemical ionization (CI), and electrospray ionization (ESI), difficult.

Nine years ago McIver et al. [1] published the first demonstration of a general solution to these problems. They showed that ions that were produced outside the magnetic field of a superconducting solenoid magnet could be transported through the fringe fields and into a cell, where they were trapped for mass analysis. Multiple differential pumping stages allowed the coupling of conventional, high gas load sources to FTMS, while maintaining cell pressures of less than $1 \times 10^{-8}$ torr. The ions were guided into the magnet via a

Address reprint requests to Dr. Sanford P. Markey, Building 10, Room 3L40, 9000 Rockville Pike, Bethesda, MD 20892. radio-frequency quadrupole, at a translational kinetic energy of between 50 and $100 \mathrm{eV}$.

Subsequently, it was shown that the rf quadrupole could be replaced with conventional electrostatic lenses to focus the ions into the region of greatest magnetic field divergence [2]. This requires careful alignment of the source with the magnetic field but permits more efficient differential pumping. Other workers have since constructed external ion source instruments dedicated to particular experiments, such as LSIMS [3], high-pressure CI [4], and ESI [5]. Two commercial external ion source FTMS systems are available (Bruker Instruments, Inc., Billerica, MA, and IonSpec Corporation, Irvine, CA). Systems are approximately evenly divided between $\mathrm{rf}$ quadrupole and electrostatic ion optics. In addition, two systems have been described which form ions outside of the cell but well within the magnetic field, so specific injection optics are avoided [6]. Finally, a system using an electrostatic ion guide for ion injection has recently been demonstrated [7].

We chose to design and construct an electrostatic lens ion transport system after noting the amnenability of electrostatic lenses to differential pumping and considering some of the properties of $\mathrm{rf}$ quadrupoles, An If quadrupole functions as a bandpass filter, with the amplitude of the trajectory oscillations increasing as the ion's mass-to-charge ratio moves further away from the midpoint of the pass band. Thus, for ions whose mass-to-charge ratio is higher than the midpoint, 
increasing $m / z$ leads to increasing excursions away from the injection axis, along with transverse kinetic energies up to twice the initial transverse kinetic energy [8]. Compounding this effect is the fact that in an FTMS system, at constant kinetic energy the cyclotron radius increases as the square root of mass-to-charge ratio, so that both the initial cyclotron radius of individual ions emerging from an rf quadrupole at the cell and the diameter of the ion beam will be an increasing function of the mass-to-charge ratio of the ions. This sets an upper limit for best performance on the range well below that predicted based simply upon the upper transmission limit of the rf quadrupole or the diameter of the FTMS cell, the magnetic field strength, and an assumed thermal energy distribution. There should also be a range of mass-to-charge ratio values which can still be trapped, but whose initial spatial and energy characteristics are sufficiently poor that they are unsuitable for high-resolution measurements. This correlates with reports of poor resolution at moderate mass-to-charge ratio values, less than 3000 , for organic ions injected via an rf quadrupole into a 7 tesla FTMS system, compared to results obtained by direct laser desorption at the cell where the resolution obtained at $m / z 5922$ was equal to the extrapolated performance specification [9]. High resolution for ions with high mass-to-charge ratio has been achieved for inorganic clusters such as cesium iodide, injected via an rf quadrupole into a 6 tesla FTMS system [10]. For example, the cluster with $m / z 9746$ was recorded with a resolution of 53,000 . However, in order to efficiently transport ions of such large mass-to-charge ratio the if voltage was sufficiently high that ions with less than $m / z 1000$ were severely discriminated against, negating the wide range detection capability of FTMS. As anticipated, an electrostatic lens system has demonstrated efficient ion transport for low and high massto-charge ratio ions, preserving the advantages of FTMS analysis.

\section{Experimental}

Experiments were performed on a standard FTMS-2000 (Nicolet, now Extrel-FTMS, Millipore Corp., Madison, WI) equipped with a dual $4.76 \mathrm{~cm}$ cubic cell assembly, AutoProbe, and $\mathrm{CO}_{2}$ laser (Tachisto Laser Systems, Boston, MA) (Figure 1): For some experiments two deflection electrodes $3 \mathrm{~mm}$ long, $2 \mathrm{~mm}$ wide, separated by $2 \mathrm{~mm}$, were added to the entrance of the first cell, alorig with a shield plate just before the deflectors, with a $4 \mathrm{~mm}$ diameter hole to match the first trap plate. The external ion source chamber was constructed by adding three half-ripples with 2.75 in. diameter flanges with OFHC copper gasket seals to a standard 8 in. flange stainless steel tee, forming a six-way cross (MDC Vacuum Products Corp., Hayward, CA). This was evacuated with a VHS-4 $800 \mathrm{~L} / \mathrm{s}$ oil diffusion pump (Varian Associates, Inc., Lexington, MA) backed by a ZM2012 $310 \mathrm{~L} / \mathrm{m}$ two-stage rotary



Figure 1. External source chamber and transfer optics. The filament would be retracted for ESI.

vane mechanical pump (Alcatel Vacuum Products, Inc., Hingham, MA). The external ion source chamber attaches to the FTMS vacuum system with standard 2.75 in. flange nipples and a pneumatic 2.75 in. flange stainless steel gate valve (High Vacuum Apparatus Mfg., Inc., Hayward, CA). Pressures were measured with uncalibrated ion gauges. The ion flight tube and lens segments were formed from 1.00 in. OD, 0.035 in. wall, 304 stainless steel tubing, and supported in the vacuum chamber with polycarbonate rings and ceramic standoffs. The source lens stack was constructed from $1.50 \mathrm{in}$. OD, 0.500 in. ID, 0.020 in. thick, 304 stainless steel disks and assembled with nylon screws and spacers. Lens potentials were supplied by standard laboratory regulated power supplies.

Ion optic modeling was performed on a Macintosh IIcx (Apple Computer, Inc., Cupertino, CA) with MacSimion 2.0 (Montech Pty. Ltd., Clayton, Melbourne, Victoria, Australia). For alignment and lens optimization a stable, long-lived source of ions was desired, so a $\mathrm{K}^{+}$thermal ionization source was constructed based upon the existing FTMS filament assembly. A mixture of $\mathrm{K}_{2} \mathrm{O}$ (as $\mathrm{K}_{2} \mathrm{CO}_{3}$ ), $\mathrm{Al}_{2} \mathrm{O}_{3}$, and $\mathrm{SiO}_{2}$, molar ratio 1:1:2, was melted together, cooled, and the resulting glass ground to a fine powder. This was melted, cooled, and again the glass ground to a fine powder to improve the homogeneity [11]. Next, a small quantity of the powder was applied to a clean rhenium filament as a slurry in isoamyl alcohol. The filament was placed in the vacuum system, evacuated to less than $1 \times 10^{-4}$ torr, and current slowly applied to the filament until it glowed yelluw-white (applied current $3.6 \mathrm{~A}$ ) for $15 \mathrm{~s}$. Upon inspection the powder had fused to form a glass bead approximately $1 \mathrm{~mm}$ in diameter. This coated filament provided $\mathrm{K}^{+}$currents of greater than $1 \mathrm{nA}$ (space charge limited at a kinetic energy of $6 \mathrm{eV}$ ), and at currents of less than $100 \mathrm{pA}$ was stable for hundreds of hours. Current measurements were made with a model 600B electrometer (Keithley Instruments, Inc., Cleveland, $\mathrm{OH}$ ).

The single-stage electrospray source was constructed along the lines of Whitehouse et al. [12], and incorporated heated $\mathrm{N}_{2}$ countercurrent bath gas, a 0.49 mm diameter skimmer (model BD-1, Beam Dynamics, Inc., Minneapolis, MN) and a ZM2033 $765 \mathrm{~L} / \mathrm{m}$ twostage rotary vane pump (Alcatel Vacuum Products, Inc., Hingham, MA). Metallized glass capillaries were 
prepared from $7 \mathrm{~mm}$ nominal OD, $0.65 \mathrm{~mm}$ ID borosilicate glass tubing which was selected for roundness, cut to length $(47 \mathrm{~cm})$, the ends ground to shape, then gold plated [13]. For some of the experiments, the single-stage electrospray source was replaced with a model 102288 two-stage electrospray source (Analytica of Branford, Branford, CT).

Chemicals were purchased from commercial suppliers and used as received. For thermal ionization, $10 \mu \mathrm{L}$ of a $1000 \mathrm{ppm}$ stock solution of $\mathrm{Ca}^{+2}$ was applied to a clean rhenium filament and air dried. The filament was then installed in the external ion source chamber and the system evacuated. Current was gradually applied to the filament until $\mathrm{Ca}^{+}$emission was detected, at which point the current was increased slightly, then maintained, providing $\mathrm{Ca}^{+}$ions for several minutes. Samples for ESI were prepared as $100 \mu \mathrm{M}$ (unless otherwise indicated) solutions in a 49.5:49.5:1 mixture of water, methanol, and acetic acid. Typical spray conditions include a liquid flow rate of $2 \mu \mathrm{L} / \mathrm{min}$ (unless otherwise indicated), needle potential of $4 \mathrm{kV}$, and an $\mathrm{N}_{2}$ flow of $3 \mathrm{~L} / \mathrm{min}$ at $350 \mathrm{~K}$.

The injected ions were trapped using either gated or accumulated trapping [14]. Gated trapping of ions whose kinetic energy is greater than a few tenths of an $\mathrm{eV}$ is hest performed by maintaining the rear trap plate at a potential sufficient to reflect the arriving ions while the potential on the front trap plate is lowered to ground for a few hundred microseconds. A large fraction of the admitted ions are then trapped when the potential is restored on the front plate. To permit efficient ion extraction and to minimize space charge effects on ion focusing and transport, typical source and trap potentials were 4-6 V. In accumulated trapping the potential is maintained on both trap plates while ions are injected for a period of time. Primarily because of collisional processes over the course of a few seconds at a pressure of $1 \times 10^{-7}$ torr, for example, a number of ions are trapped, or accumulated, in the cell. This process can be enhanced for ions with $\mathrm{m} / \mathrm{z}$ less than 100 by using deflector plates at the cell entrance or by applying a differential bias of a few volts across the transmitter plates to shift the electrical center of symmelry away from the physical axis along which the ions are injected [15]. Unless otherwise indicated, no transmitter bias was applied and the deflector plates, if present, were maintained at ground potential. Another possible means of increasing the efficiency of ion accumulation when the cell pressure is less than optimum is to admit a pulsed collision gas $[5 b, 16]$.

\section{Results and Discussion}

\section{System Design}

In order for the external ion source assembly to have minimal impact on the existing FTMS-2000, it was decided to attach it to the "analyzer cell" region, furthest from the AutoProbe direct insertion probe apparatus and traditionally the lower pressure (thus higher performance) cell region. Ions produced externally could be introduced into this first cell, or transported through the $2 \mathrm{~mm}$ conductance limit into the second, now lower pressure, "source cell." The terms source and analyzer are the manufacturers' designations for the two cells of the FTMS-2000 dual cell instrument. In this paper the terms first and second cell will be used to indicate the order in which injected ions encounter the cells. Injected ion current can be monitored on the cell plates or on a collector over the second-cell region diffusion pump, furthest from the external ion source and outside the region of greatest magnetic field. While the first cell is centered in the region of greatest magnetic field homogeneity, this should not limit the performance of the second cell in the mass-to-charge ratio range of interest (greater than $m / z 100)[17]$.

By retaining the two cells and taking advantage of the existing differential pumping between them, no extra differential pumping stages need to be added hetween the external ion source chamber and the FTMS. For multiple stages of differential pumping, given two regions, 1 and 2, separated by an opening of conductance $C_{1,2}$ and region 2 pumped with a speed of $S_{2}$, the pressure ratio $P_{1} / P_{2}$ is approximately $\left(S_{2} / C_{1,2}\right)+$ 1. The larger the orifice the simpler the system alignment and the ion optics design but the lower the pressure ratio. Estimating the net pumping speed at the cells as $400 \mathrm{~L} / \mathrm{s}$, a $2 \mathrm{~mm}$ orifice gives a pressure ratio for air of 1100 . This is adequate assuming a maximum external ion source chamber pressure of $1 \times 10^{-3}$ torr, producing a predicted pressure of $9.1 \times$ $10^{-7}$ torr in the first cell and $1 \times 10^{-9}$ torr (below the system base pressure of approximately $3 \times 10^{-9}$ torr) in the second cell. For maximum gas throughput the external chamber was made from an 8 in. flange stainless steel tee (with $6.00 \mathrm{in.}$ OD tubing). Ions are formed or introduced in the center of the tee over the pump throat.

Measured pressure ratios differ somewhat from these estimates because of the relative locations of the ion gauge lubes, the pumps, and the point of gas introduction into the system. The majority of gas from the external ion source will travel through the flight tube and enter the FTMS at the first cell, while the ion gauge tube is located on a sidearm attached above the pump throat and thus will indicate a pressure lower than the actual cell pressure. In the same way, the gas that passes through the cell conductance limit will cause the pressure in the second cell to be higher than the indicaled pressure. System base pressures are 0.3 $\times 10^{-8}$ torr in each cell region and $4 \times 10^{-8}$ torr in the external chamber. Typical pressures observed while admitting $\mathrm{N}_{2}$ gas via the ESI source are $6 \times 10^{-4}$, $1.8 \times 10^{-7}$, and $0.9 \times 10^{-8}$ torr in the external chamber, the first-cell region, and the second-cell region, respectively. This corresponds to indicated pressure 
ratios of 3300 and 20 . As previously discussed, the measurement overestimates the pressure difference between the external chamber and the first cell, and underestimates the pressure ratio between cells. In any case, even with a high gas load source such as ESI, the pressure in the first cell is suitable for medium resolution measurements, and the pressure in the second cell is adequate for high resolution work. It should be noted that the instrument resolution specification is 900,000 for ions with $m / z 131$ from in-cell electron impact of perfluoro-tri-n-butylamine, with a magnetic field strength of 3 tesla. This requires a transient lifetime of 3 to $4 \mathrm{~s}$, and is usually met with an indicated pressure of $0.5-0.8 \times 10^{-8}$ torr (FTMS-2000 specifications, Extrel-FTMS, Millipore Corp., Madison, WI).

Three ion lenses are used (see Figure 1). The first, the source lens, accelerates the ions and focuses them through the $2 \mathrm{~mm}$ orifice and into the flight tube. A second lens, the gate valve lens, refocuses the expanding beam emerging from the orifice and focuses it into the fringe field of the 3 tesla superconducting solenoid magnet. This lens provides a gap in the flight tube sufficient to incorporate a 2.75 in. flange stainless steel gate valve for system isolation. Finally, a lens at the cell decelerates the ions as they emerge from the flight tube and enter the first cell. The mechanical layout, including the position of the gate valve and the approximate position of the orifice, was chosen first. The flight tube is actually composed of two segments, one extending from the orifice (which is at the same potential as the flight tube) to the gate valve lens, and a second segment extending from the gate valve lens to the cell. Following the arguments set forth in Ref. [4], there is a small benefit in keeping the ions at their maximum kinetic energy as they penetrate the mag netic field (to minimize the ratio of transverse to axial kinetic energy). The higher the kinetic energy the smaller the conductance limiting orifice can be for a given size source (the diameter of the source object which is to be projected into the magnetic field). However, previous experience has shown that discharges are problematic when electrodes are arranged at high potential with cylindrical symmetry about the magnetic field [4, 6a]. Also, with large accelerating potentials, there is the danger of inadvertently collisionally activating ions in the high pressure region of the external ion source chamber. Based on these considerations it was decided to limit the flight tube potential to a few hundred volts.

Given the specified source object diameter of $2 \mathrm{~mm}$ and an orifice diameter of $2 \mathrm{~mm}$ the source lens must provide a magnification of one or less, while accelerating the ions to energies of several hundred $\mathrm{eV}$. One means of minimizing lens aberrations is to minimize the fraction of lens cross-sectional area the ions traverse (the fill factor). To provide maximum gas throughput and a fill factor below $40 \%$ for typical ions, the source lens was constructed with 0.500 in. apertures spaced 0.500 in. apart from three disks whose diameter is three times the aperture diameter. The front plate is at ground potential (located 0.75 in. from the design source object), and the rear plate is at flight tube potential. The gap between this plate and the orifice $(0.75 \mathrm{in}$.) is surrounded with $50 \%$ transmissive 304 stainless steel mesh to provide high conductance and a field-free region. The potential on the central plate is varied to control focal properties in a standard triode lens arrangement [18]. The magnetic field at the source lens is 0.015 tesla, sufficiently weak that only electrons are deflected significantly.

A gap in the flight tube large enough to accommodate a gate valve creates a very strong lens, with a maximum focal length of a few inches. To overcome this, a second gap was added between the orifice and the gate valve. The first gap forms an image of the orifice between the two gaps, and the second gap images this new "point source" into the magnet. To minimize aberrations the two gaps are equal, the distance from the orifice to the first gap is the same as the length of the lens segment, and the lens segment is the same diameter as the flight tube. It is possible to operate this lens in either accelerating or decelerating mode. The former should provide slightly better performance but would require a potential of a few thousand volts, so the decelerating mode was chosen instead. For a source potential of $6 \mathrm{~V}$ and flight tube potential of $-200 \mathrm{~V}$, the corresponding gate valve lens potential is $-33 \mathrm{~V}$. Due to field penetration the minimum kinetic energy of the ions while traversing the lens segment is a few $\mathrm{eV}$ above the difference between the source potential and $-33 \mathrm{~V}$. The diameter of the flight tube (1.00 in. OD) was chosen to fit within the $1.50 \mathrm{in.} \mathrm{OD} \mathrm{tubing} \mathrm{used} \mathrm{with} 2.75 \mathrm{in}$. flange stainless steel fittings, and the position of the gate valve was dictated by the lengths of standard nipples, gate valves, and tees. This leads to a somewhat poor fill factor of between 50 and $60 \%$, and some ions with extreme trajectories (originating at the edges of the source object) are lost. The magnetic field is increasing in the region of the gate valve lens, with an average value of 0.03 tesla. This has the effect of rotating the image slightly and increasing the focal length a few percent for ions heavier than electrons. At these potentials electrons will follow the magnetic field lines, simply accelerating and decelerating as they traverse each gap.

Finally, the ions must be decelerated to a kinetic energy less than the trap potential. As the cell potential is referenced to ground, the encrgy of the ions is given by the source potential minus any energy converted to cyclotron motion as the ions traverse the magnetic mirror region [4]. For the reasons given above the ions are kept at maximum kinetic energy until just before the cell. Because the magnetic field also acts as a condensing lens the image of the beam formed by the gate valve lens (about $3 \mathrm{~mm}$ diameter in a region of rapidly increasing magnetic field) is reduced to less than $2 \mathbf{~ m m}$ at the cell. This ion image corresponds to a 
fill factor in the flight tube of less than $8 \%$. Near the $z$-axis the electric field created by the gap between the flight tube and the short grounded segment adjacent to the first cell is approximately perpendicular to the ion's motion. Given the very low fill factor, this allows uniform deceleration of the ions without significant deflection. Simulations show that decelerated ions gain much less than $0.1 \mathrm{eV}$ transverse kinetic energy, obviating the need for more complex structures such as an exponential deceleration lens [19].

\section{Alignment and Optimization}

The system was assembled and aligned in stages. First, the chamber position in the magnet was verified in the usual way. The filament was installed in its normal position and several microamperes of $70 \mathrm{eV}$ electrons directed towards the cell. The filament was centered in the chamber by viewing through the window located directly behind it. The chamber mounts were loosened and the chamber centered in the magnet bore. The cell trap plates, conductance limit, and collector were monitored for current using an oscilloscope, and the chamber positioned to maximize the collector current while minimizing the current intercepted by the cell plates. The beam diameter at the cell is somewhat less than 2 $\mathrm{mm}$, and so there is a range of chamber positions which cause no current to be detected on the conductance limit. The chamber was centered within this range both left-right and up-down. Finally, the filament was removed and the external ion source chamber and flight tube assembly installed, and the filament was then centered in the external chamber by again maximizing the collector current with all lenses af ground potential. Because the magnetic field dominates the transverse motion of $70 \mathrm{eV}$ electrons even at 0.015 tesla, the field at the filament location in the external chamber, this provides a good way to achieve initial mechanical alignment of the ion flight path with the magnetic field.

However, it was still necessary to make the electrical axis of symmetry in the first cell coincide as closely as possible with the injected ion beam, and this must be done with ions more massive than electrons so that they are properly focused by the lens system. Thus, the $\mathrm{K}^{+}$filament was installed and tested. A typical filament current of $1.4 \mathrm{~A}$ produced stable $6 \mathrm{eV} \mathrm{K}^{+}$currents of $100 \mathrm{pA}$. The total ion current at the source lens was measured by retracting the filament until the sum of the currents striking the orifice and the lens plates was maximized. Then the filament was recentered, the flight tube potential established, and the collector current monitored as the two lens potentials were adjusted. Starting values were determined from the modeling studies, and were within $15 \%$ of final values. Periodically during this tuning the filament position was adjusted to maximize the collector current. After an optimum combination of source lens and gate valve lens potentials was found, the current interrupted by the cell conductance limit was determined to be less than $5 \%$ of the collector current. Gated trapping measurements were then made to compare the abundances in each cell, and a pulse sequence consisting of gated trapping in the first cell, followed by a variable delay. then a timed transfer event, and finally excitation/detection in the second cell was used to monitor the evolution of magnetron motion of the ions trapped in the first cell. By varying the delay from zero to a few milliseconds, the abundances were observed to vary in a somewhat sinusoidal fashion [20]. The peak-to-peak abundance difference reflects how misaligned the cell is with respect to the magnetic field and how far from the cell's electrical center of symmetry the ions are injected. The end of the FTMS chamber containing the second cell was fixed in place, and the external chamber and the first-cell end of the FTMS chamber were repeatedly repositioned (by venting, separating the two, moving them, then reassembling to avoid bending stresses on the flanges) to minimize this magnetron motion. After each adjustment the filament position was reoptimized to provide maximum collector current.

The final alignment resulted in gated trapping abundances within $5 \%$ of each other in the two cells and a peak-to-peak abundance variation due to magnetron motion of $60 \%$ (see Figure 2). These measurements were made with a $\mathrm{K}^{+}$current at the collector of $16 \mathrm{pA}$ and the current on the cell conductance limit was $0.26 \mathrm{pA}$. The flight tube potential was varied from -30 to $-500 \mathrm{~V}$, and while $-200 \mathrm{~V}$ was found to be optimum, values between -100 and $-300 \mathrm{~V}$ resulted in less than a $50 \%$ drop in collector current. Optimum potentials for the source lens, gate valve lens, flight tube, and filament were $-64.5,-32.1,-200$, and $+4.0 \mathrm{~V}$, respectively. With these values, $29 \%$ of the ion current which reached the source lens was transmitted into the magnet, through the cells, out of the magnet, and measured at the collector. This transfer efficiency is dependent on the dimensions of the emitter, and was achieved with the $1 \mathrm{~mm}$ diameter source. For



Figure 2. Time course of magnetron motion of trapped ions about the electrical axis of symmetry in the cell, showing the overlap of the ion cloud with the conductance limit separating the two cells. The curve is the best fit exponentially-damped sinusoid, with $R^{2}=0.94$. 
comparison, a second source was constructed with a glass bead approximately $1 \mathrm{~mm}$ wide and $5 \mathrm{~mm}$ long, and this yielded an overall transmission efficiency of $10 \%$. Measurements showed that the majority of the lost ions were striking the $2 \mathrm{~mm}$ orifice, consistent with the design magnification of the source lens.

\section{Thermal Ionization}

As a first test of system performance the $\mathrm{K}^{+}$filament was installed and the system pumped to pressures of $5.3 \times 10^{-7}, 1.1 \times 10^{-8}$, and $0.5 \times 10^{-8}$ torr in the external chamber, first-cell region, and second-cell region, respectively. Gated trapping was performed in the second cell with heterodyne mode detection and the ions with $m / z 39$ were recorded at a resolution of 574,000 (full width at half-height definition). An alternative experiment is to perform accumulated trapping in the first cell, at higher pressure to enhance the efficiency, and then to transfer the ions to the second cell for analysis at lower pressure. By accumulating for $5 \mathrm{~s}$ with $0.25 \mathrm{~V}$ applied differentially to the first-cell transmitter plates, then transferring, the $\mathrm{K}^{+}$ions with $m / z 39$ were recorded with a resolution of $1,700,000$. The increase in resolution is due primarily to the greater abundances possible with accumulated trapping [21].

Finally, $10 \mu \mathrm{g}$ of Ca was applied to a clean filament and spectra acquired by gated trapping in the first cell with broad band, direct mode detection while the filament current was slowly increased. The most abundant isotope, with $m / z 40$, was ejected to maximize the available dynamic range. The second most abundant isotope, with $m / z \quad 44$ and natural abundance $2.15 \%$, was recorded with a resolution of 20,000 and with a signal-to-noise ratio of $\mathbf{3 2}$ (Figure 3). Also visible are other $\mathrm{Ca}$ isotopes, including ${ }^{43} \mathrm{Ca}$, whose natu$\mathrm{ral}$ abundance is $0.15 \%$.

\section{ESI}

After verification of the external ion source system by thermal ionization, an ESI source was constructed.

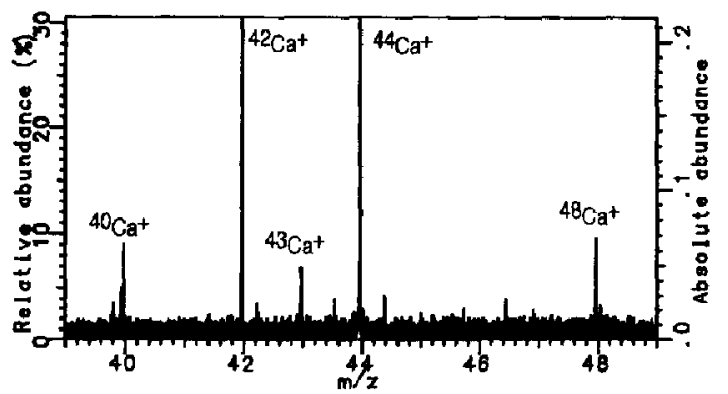

Figure 3. Thermal ionization spectrum of $\mathrm{Ca}^{+}$acquired from 10 $\mu \mathrm{g}$ Ca by gated trapping in the first cell with ejection of the ions with $m / z 40$. The spectrum is plotted so that ${ }^{44} \mathrm{Ca}$ is off-scale. The natural abundance of ${ }^{43} \mathrm{Ca}$ is $0.15 \%$. which incorporated a single extra stage of differential pumping. The ESI source provided total ion currents of less than $5 \mathrm{pA}$ at the source lens, and much less than 1 $\mathrm{pA}$ at the first cell. Even with the heated countercurrent gas some fraction of this current is due to residual charged droplets, making an accurate determination of sample ion injection efficiency problematical. Comparison of ESI ion abundances with thermally generated $\mathrm{K}^{+}$abundances indicates that sample ion currents at the first cell were on the order of $0.1 \mathrm{pA}$. Operating pressures were $1.2,6 \times 10^{-4}, 1.8 \times 10^{-7}$, and $0.9 \times 10^{-8}$ torr in the first stage, external chamber, first-cell region, and second-cell region, respectively.

Initial tuning was performed with cetylbenzyldimethylammonium chloride. This compound yielded abundant $[\mathrm{M}-\mathrm{Cl}]^{+}$ions at $m / z 360$ detectable after accumulation times of 1 to $5 \mathrm{~s}$ in the first cell. Transfer to the second cell was possible, but the efficiency was less than $10 \%$. Long accumulation times lead to collisional growth of the magnetron radius, limiting ion transfer to the most recently accumulated ions. This was indicated by a constant second-cell abundance for accumulation times greater than $10 \mathrm{~s}$, while the first-cell abundance continued increasing with accumulation times as long as $90 \mathrm{~s}$. Next, polyethylene glycol 3400 was investigated. This sample yielded either singly, doubly, or triply charged molecular ions, of low abundance, formed from $\mathrm{Na}^{+}$addition. The charge state was a sensitive function of the capillary exit potential, with higher potentials imparting greater translational energy and thus greater collisional activation, leading to lower charge states (see Figure 4). The optimum injection lens potentials for both of these spectra were the same, showing that the electrostatic ion injection system does not limit the wide mass-to-charge ratio range available with FTMS.

With electrosprayed polyethylene glycol, the ion abundances in the first cell were insufficient to allow transfer to the second cell for examination at high resolution. The advantage of the transfer is that it requires less than a millisecond. However, due to the extremely weak sample currents at the first cell, accumulation times of $30-120 \mathrm{~s}$ are required. Given this, an experiment sequence was developed which accumulates ions for an extended period with the trap potentials set to give the greatest abundance $(4-6 \mathrm{~V})$, then the pneumatic gate valve is closed under computer control. The first-cell pressure is reduced to less than $0.8 \times 10^{-8}$ torr in about $10 \mathrm{~s}$. At the same time, the trap potential is reduced to $0.3 \mathrm{~V}$ to improve peak shape and mass resolution. The pressure stabilizes $15 \mathrm{~s}$ after closing the valve, and the trapped ions are then excited and detected. After detection, the cell is quenched and the valve reopened to permit another accumulation period. Figure 5 shows a spectrum of Gramicidin $S(30 \mu \mathrm{M})$ recorded at a resolution of 90,000 for the $[\mathrm{M}+\mathrm{Na}]^{+}$ion with $m / z$ 116t, resulting from a single 30 second accumulation. This resolution is about $10 \%$ less than the extrapolated instrument 

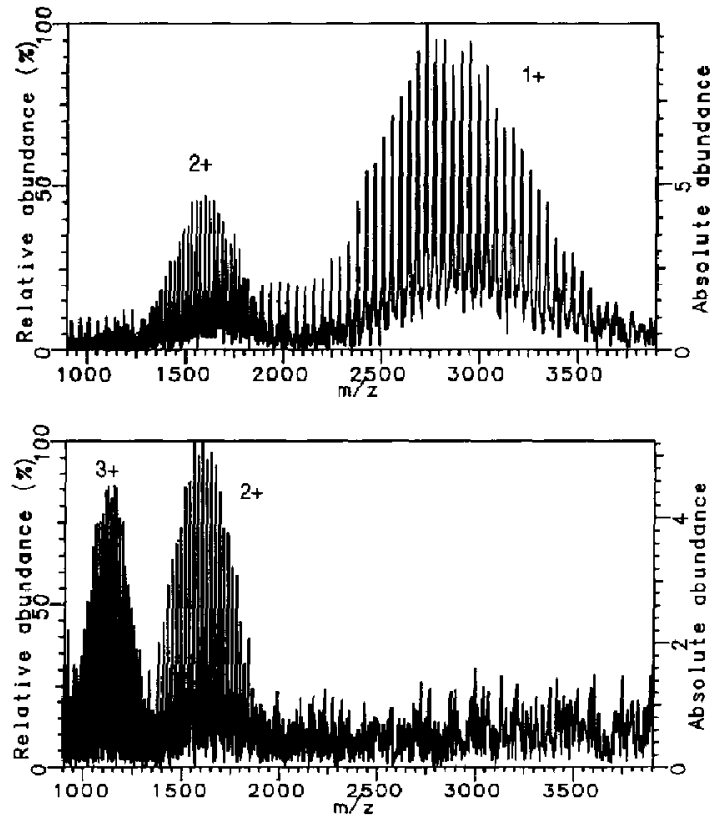

Figure 4. ESI spectra of PEG 3400, at a concentration of $100 \mu \mathrm{M}$, obtained with the single-stage source. The top spectrum is the result of the co-addition of 24 accumulations of $120 \mathrm{~s}$ each with a capillary exit potential of $300 \mathrm{~V}$, while the lower spectrum was acquired by co-adding 12 accumulations of 120 s each with a capillary exit potential of $200 \mathrm{~V}$.

specification, and indicates that externally generated organic ions can be detected with performance similar to that obtained by in-cell ionization.

An example of a larger protein is horse heart cytochrome $c$, molecular weight 12,360 , shown in Figure 6. The ions in this spectrum result from mixed $\mathrm{Na}^{+}$ and $\mathrm{H}^{+}$attachment with the charge states as labeled. As previously noted in electrospray ionization Fourier transform mass spectrometry (ESI/FTMS), the most abundant charge state is $8^{+}$, in contrast to typical spectra obtained on quadrupole instruments where

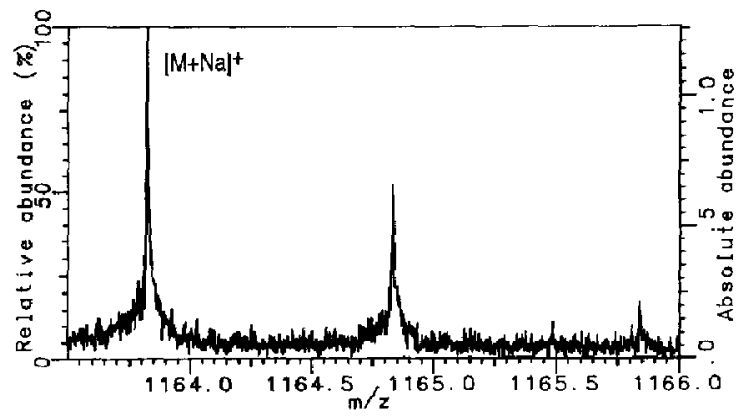

Figure 5. ESI spectrum of Gramicidin $S$ at a concentration of 30 $\mu \mathrm{M}$ with a resolution of 90,000 . This is the result of a single $30 \mathrm{~s}$ accumulation obtained with the single-stage source.


Figure 6. ESI spectra of horse heart cytochrome $c$, at a concentration of $100 \mu \mathrm{M}$ obtained with the single-stage source. The top spectrum is the result of the co-addition of 50 accumulations of 5 $\mathrm{s}$ each, while the lower spectrum was acquired by co-adding 2 accumulations of $90 \mathrm{~s}$ each.

$14^{+}$is the most abundant [5b]. To rule out charge transfer reactions with background species during the long accumulation times, two different accumulation times were used to acquire these spectra. The top spectrum represents 50 co-added accumulations of $5 \mathrm{~s}$ each, while the lower spectrum was acquired by coadding 2 accumulations of $90 \mathrm{~s}$ each. The charge state distributions are the same, indicating that, at least for this sample, ion-molecule reactions with background species are not responsible for the lower charge state distribution. These spectra also demonstrate that when employing ion accumulation without remeasurement, the maximum signal-to-noise ratio is obtained in a given time perind by accumulating for the entire period. The signal grows linearly with time during accumulation, while the noise is proportional to the square root of the number of co-added scans. The limit is reached when the accumulated signal no longer increases with time, either due to trapping losses at the moderately high pressure in the cell or to space charge. For this system, maximum accumulation times of 90 to $120 \mathrm{~s}$ are typical. Experiments in which additional gas was added to the cell while accumulating ions produced by ESI did not result in increased ion abundances but did reduce the maximum accumulation time due to scattering losses to less than $90 \mathrm{~s}$. 
Following these preliminary results a two-stage electrospray source was interfaced to the external ion source chamber. Operating pressures remained the same, but sensitivity was improved by at least a factor of 50. For example, with cytochrome $c$ at a concentration of $8 \mu \mathrm{M}$ and flow rate of $1 \mu \mathrm{L} / \mathrm{min}$, the space charge limit of the cell is reached in $30 \mathrm{~s}$. Because of the shorter accumulation times required to obtain adequate ion abundances, ion transfer efficiency to the second cell is improved to greater than $10 \%$. For example, the $8^{+}$and $9^{+}$charge states of cytochrome $c$ were (simultaneously) recorded with an average resolution of 50,000 in the second cell (see Figure 7). This twostage ESI source is identical to one installed on a quadrupole mass spectrometer in our laboratory, and this same solution yields $14^{+}$as the most abundant charge state on that system, while, as with the singlestage source, $8^{+}$is the most abundant charge state recorded with the FTMS. Experiments with flight tube potentials as low as $-80 \mathrm{~V}$ and as high as $-400 \mathrm{~V}$ yielded the same charge state distribution, arguing against collisional activation in the acceleration region. The most likely hypothesis for the differing charge state distributions is that the extended time scale of the FTMS experiment compared to the quadrupole mass analyzer ( $2 \mathrm{~s}$ versus $100 \mu \mathrm{s}$ ) results in the observation of metastable decay following collisional activation in the capillary-skimmer region.
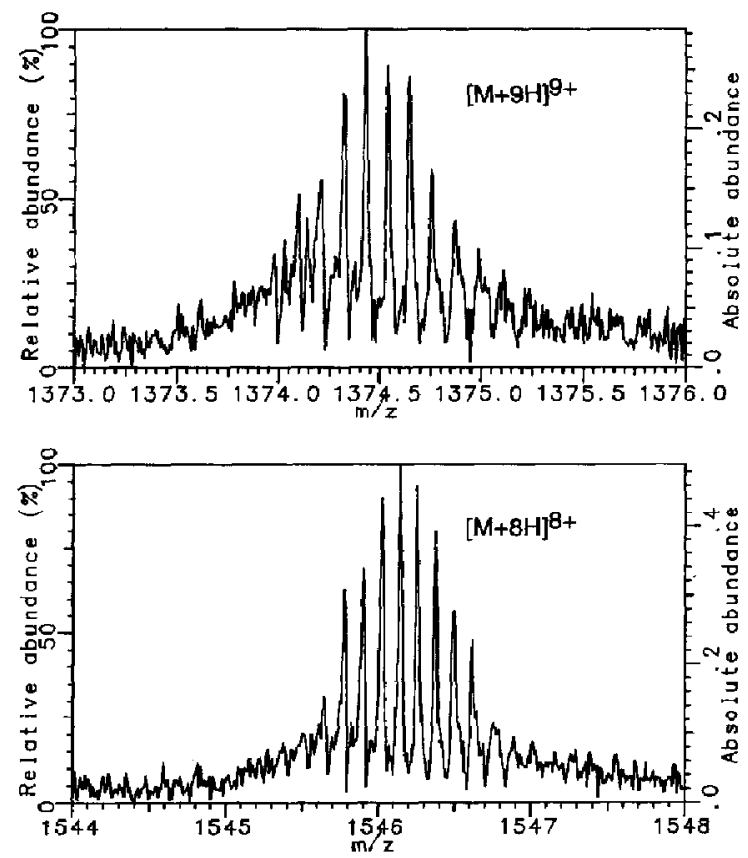

Figure 7. Two regions from a single ESI spectrum of horse heart cytochrome $c$, at a concentration of $8 \mu \mathrm{M}$ and flow rate of 1 $\mu \mathrm{L} / \mathrm{min}$. This is the result of the co-addition of 16 accumulations of $10 \mathrm{~s}$ each, obtained with the two-stage source. The average resolution is 50,000 .
As a final example. of the performance obtained with this 3 tesla ESI/FTMS system, a $10 \mu \mathrm{M}$ solution of the small protein aprotinin, molecular weight 6512 , in 1:1 water and methanol, was infused at a flow rate of $1 \mu \mathrm{L} / \mathrm{min}$. By accumulating in the first cell and then closing the gate valve, the $5^{+}$charge state was recorded with an average resolution of 410,000 (see Figure 8).

\section{Conclusions}

An ion transport system that interfaces external ion sources with a commercial dual-cell FTMS system so as to retain maximum experimental flexibility has been designed, constructed, and tested. Electrostatic lenses were used for ion transfer with potentials less than 200 $\mathrm{V}$ to prevent discharges and collisional activation in the acceleration region of the source, and to allow efficient differential pumping. Transfer efficiency of ions to the cells was measured to be approximately $30 \%$ and a pressure ratio of $10^{5}$ between the external ion source chamber and the second cell has been demonstrated. The advantages of an external ion source appear to have been met with this assembly, in that sample introduction can be achieved readily and independently of the performance of the mass analyzer. The system incorporates a computer-controlled gate valve to isolate the cell regions from the external ton source chamber. The isolation valve allows ion injection and accumulation at moderately high pressures, and then by closing the valve and delaying $15 \mathrm{~s}$, spectra can be recorded at low pressure with high resolution. Results include the observation of $[\mathrm{M}+$ $\mathrm{Nal}^{+}$ions, with $m / z$ 1164, from Gramicidin $S$ at a resolution of 90,000 ; and $[\mathrm{M}+5 \mathrm{H}]^{5+}$ ions, with $\mathrm{m} / \mathrm{z}$ 1304 , from aprotinin at a resolution of 410,000 . Other ionization techniques can be easily added to the external ion source chamber, such as liquid secondary ion mass spectrometry and glow discharge ionization.

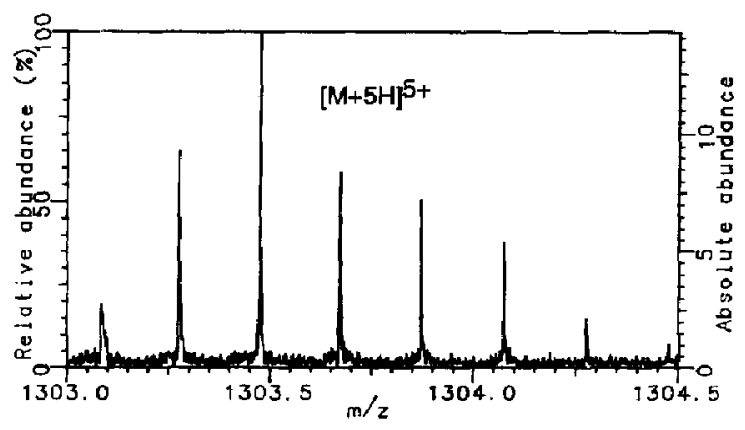

Figure 8. ESI spectrum of aprotinin, at a concentration of 10 $\mu \mathrm{M}$ and flow rate of $1 \mu \mathrm{L} / \mathrm{min}$, obtained with the two-stage source. This is the result of a single $6 \mathrm{~s}$ accumulation, and the average resolution is 410,000 . 


\section{Acknowledgments}

This work was supported by the Intramural Research Program of the National Institute of Mental Health. CFI gratefully acknowledges the National Research Council for fellowship support.

\section{References}

1. (a) McIver, R. T. Ir.; Hunter, R. L; Story, M. S.; Syka, J.; Labunsky, M. Fresented at the Thirty-First Annual Conference on Mass Spectrometry and Allied Topics, Boston, MA, May 1983; (b) U. S. Patent No. $4,535,235$.

2. (a) Kotel, P.; Allemann, M.; Kellerhals, Hp.; Wanczek, K.-P. Int. J. Mass Spectrom. Ion Processes 1985, 65, 97-103; (b) Alford, J. M.; Williams, P. E.; Trevor, D. J.; Smalley, R. E. Int. J. Mass Spectrom. Ion Processes 1986, 72, 33-51.

3 (a) Hunt, D. F.; Shabanowitz, J.; McIver, R. T. Jr.; Hunter, R. L.; Syka, J. E. P. Anal. Chem. 1985, 57, 765-768; (b) McCullough, S. M.; Gard, E.; Lebrilla, C. B. Int. I. Mass Spectrom. Ion Processes 1991, 107, 91-102.

4. Kofel, P.; McMahon, T. B. Int. J. Mass Spectrom. Ion Proc. 1990, 98, 1-24.

5. (a) Henry, K. D,; McLafferty, F. W. Ory. Mass Spectrom. 1990, 25, 490-492; (b) Winger, B. E.; Hofstadler, S. A.; Bruce, J. E.; Udseth, H. R.; Smith, R. D. I. Am. Soc. Mass Spectrom. 1993, 4, $566-577$.

6. (a) Ijames, C. F.; Wilkins, C. L. J. Am. Soc. Mass Spectrom. 1990, 1, 208-216; (b) Hofstadler, S. A.; Laude, D. A. Jr. Anal. Chem. 1992, 64, 569-572.
7. Limbach, P. A.; Marshall, A. G.; Wang, M. Int. J. Mass Spectrom. Ion Processes 1993, 125, 135-143.

8. Dawson, P. H. In Quadrupole Mass Spectrometry and its Applications; Dawson, P. H., Ed. Elsevier: Amsterdam, 1976; pp. 15-23.

9. Ijames, C. F. Wilkins, C. L. I. Am. Chem. Soc, 1988, 110, $2687-2688$.

10. Lebrilla, C. B.; Amster, I. J: McIver, R. T. Jr. Int. J. Mass Spectrom. Ion Processes 1989, 87, R7-R13.

11. Blewett, J. P.; Jones, E. J. Phys. Rev. 1936, 50, 464-468.

12. Whitehouse, C. M.; Dreyer, R. N.; Yamashita, M.; Fenn, J. B. Anal. Chem. 1985, 57, 675-679.

13. Yang, P. W. J.; Ethridge, E. L.; Lane, J. L.; Griffiths, P. R. Appl. Spectrose, 1984, 38, 813-816.

14. Beu, S. C.; Laude, D. A. Ir. Int. J. Mass Spectrom. Ion Processes 1991, 104, 109-127.

15. U. S. Patent $4,924,089$.

16. Beu, S. C.; Senko, M. W.; Quinn, J. P.; Wampler, R. M. III; McLafferty, F. W. I. Am. Soc. Mass Spectrom. 1993, 4, 557-565.

17. Laukien, F. H. Int. J. Mass Spectrom. Ion Processes 1986, 73, $81-107$.

18. Klemperer, O.; Barnett, M. E. Electron Optics, 3rd edn., Cambridge University Press: London, 1971; p. 325.

19. Vestal, M. L.; Blakley, C. R.; Ryan, P. W.; Futrell, J. H. Rev. Sci. Instrum. 1976, 47, 15-26.

20 Honnvich, J. P.; Markey, S. P. Int. J. Mass Spestrom. Ion Processes 1990, 101, 21-34.

21. Rempel, D. L.; Grese, R. P.; Gross, M. L. Int. J. Mass Spectrom. Ion Processes, 1990, 100, 381-395. 